\title{
Sexual Aggressive Behaviour Amongst Adolescent Males: A Challenge for South African Parents, Schools and Society at Large
}

\author{
J.G. Kheswa \\ M. Notole \\ Department of Psychology, University of Fort Hare, \\ Private BagX1314, Alice, South Africa \\ Email: jkheswa@ufh.ac.za
}

\section{Doi:10.5901/mjss.2014.v5n10p484}

\begin{abstract}
Socio-cultural theory advocates that sexual aggressive behaviour of adolescent males is socially mediated, historically and culturally conditioned. Boys, who were reportedly socialized from an early age into traditional patriarchal notions of masculinity, legitimize unequal gendered power relations. In addressing the sexual aggressive behaviour of adolescent males, the literature from previous research studies, academic journals, books and internet sources were reviewed. The research findings reveal that adolescent males raised by permissive and uninvolved parents, tend to engage in risky sexual behaviour and consequently face a bleak future, imprisonment and contract sexually transmitted infections. Appropriate interventions such as transmission of values and principles in the family, and establishment of campaigns by older adult males may have a positive impact on young males in reducing an escalating rate of victimization of females.
\end{abstract}

Keywords: sexual behaviour, aggression, adolescent male, parents, culture

\section{Introduction}

Aggressive sexual behaviour is a worldwide problem and a rising concern especially for rural adolescent males in the African continent. Aggression is the thought of hatred that may result in aggressive or threatening behaviour. From biomedical model, sexual aggression of adolescent males is defined as a behaviour which emanates from imbalance in neurotransmitters, for example low serotonin level is strongly associated with anti-social behaviour (Nicholas, 2008). In addition, aggression implies the intent to sexually harm other person who is perceived to be vulnerable for sexual gratification of the perpetrator (Sadock \& Sadock, 2007). The prevalence of sexual aggressive behaviour among adolescent males varies across countries (Garcia- Moreno, Jansen, Ellsberg, Heise \& Watts, 2006; Mwinga, 2012). However, in South Africa, adolescents and young people constitute $26 \%$ of the country's population. In research by Burton (2007), adolescence (age between13-18) is the peak stage for both offending and victimization of sexual offences. Therefore, it is obvious that huge percentage of South Africa's population falls within the high risk age group of being perpetrators or victims of sexual crime. In the Eastern Cape, aggressive sexual behaviour of adolescent boys has gradually become under spotlight due to the negative consequences it has on the youth (Swart, de la Rey, Duncan \& Townsend, 2008). Eastern Cape is predominantly rural, consequently has increased the probability of male adolescents to engage in aggressive sexual activities. In support of this, Mwinga (2012) revealed that sexual aggressive behaviour is a common practice amongst rural secondary school adolescent males.

\section{Methodology}

de Vos, Fouche, Strydom and Delport (2011) state that the reviewing of related literature is aimed at contributing at a clearer understanding of the nature and meaning of the problem that has been identified. Hence the researcher must ensure that nobody else has conducted the equivalent research. Mouton (2012) describes review of literature as a guiding map for the researcher. He further concurs that review of related literature provide guidelines and suggest design to be used in the study. It helps to get a deeper insight and more knowledge about the research problem (de Vos et al., 2011; Mouton, 2012). For this research paper, the related research studies, academic journals, books and internet sources have been reviewed to get an overview and address the challenges faced by parents, schools and societies at large caused by sexual aggressive behaviour of adolescent males. 


\section{Theories of Sexual Aggressive Behaviour}

Drawing from Dollard's frustration-aggression hypothesis (Sadock \& Sadock, 2007), adolescents who have sexually violated or who were perpetrators of sexual violence tend to be socially withdrawn and frustrated. It is that frustration which makes them to be more sexually aggressive among other adolescents including their sexual partners. Arguably, Breet, Myburgh and Poggenpoel (2010) point that all people irrespective of their age, gender or culture express their frustrations and emotions in aggressive behaviours including sexual aggressiveness. From Marshall and Barbaree's integrated theory, Ward (2002), suggests that human beings are complex creatures. Thus, human behaviour should be considered from distinctive viewpoints, for example, biologically, social-culturally and psychologically. This brings an idea that, male adolescent males' sexual desires are biologically involuntary. Such influences originate from the strong desire to gratify sexual pleasure. Drawing from psychosocial developmental theory by Erik Erickson, during the fifth stage identity versus role confusion (Louw \& Louw, 2007), adolescent males in particular are in pursuit of sexual identity, establishment of their own value system and right attitude to sex. However, when there is a lack of cognitive stimulation, warmth and sense of independence from parents, school and the society, identity diffusion may manifest in the form of sexual aggressive behaviour (Engler, 2014; Weiten, 2011). Similarly, the developmental theories point out that adolescent stage could be both exciting and challenging as it is characterized by heightened sexual awakening, cognitive, emotional and psychosocial developments (Bee \& Boyd, 2003; Jansen, Moletsane, Neves, Soudien, Stroud, Swart \& Wild, 2012; Papalia, Olds \& Feldman, 2009). Drawing from psychoanalytic approach by Sigmund Freud, adolescence begins around the onset of puberty and ends at the adoption of adult roles. The development of adolescent varies from 11 to 18 (Jansen et al., 2012). Adolescents are said to experience puberty during genital stage which is characterized by the development of secondary characteristics. Boys' penises enlarge in length and thickness and while asleep experience wet dreams (nocturnal emission) which indicates that they can make off-spring should they practice unsafe sex with girls. Puberty is described as a period of development characterized by rapid physical maturation which includes physical and biological changes that occur during adolescence stage (Swartz et al., 2010).

Biologically, there is no direct link between biological causes and sexual aggression, but some neuro-chemical imbalances in the body predisposes adolescents to aggressive sexual practices (Sadock \& Sadock, 2007; Stevens \& Cloete, 2010). Sexual aggression of adolescent males is a behaviour which originates from chemical imbalance precisely neurotransmitters (Nicholas, 2008). According to Katy, Jeff, Scott, Vijay, Molly, David, Jackie, Salome and Susan (2002), hormones play a significant role in the tendency of adolescent boys to behave aggressively. Males tend to be more aggressive than females and these sex variations are linked to hormones of testosterone before and during birth.in contrast, testosterone is not the only hormone associated with aggression, but serotonin which is associated with depression lead people to behave impulsively (Sadock \& Sadock, 2007), it is that impulsiveness that makes adolescent boys to be sexually aggressive amongst others. The study by Bernstein, Penner, Clarck-Stewart and Roy (2008), discovered that, children of women who had used testosterone during their pregnancy with the aim to prevent miscarriage became more aggressive as compared to children who had never been exposed to testosterone during their prenatal development. Adolescent males who are convicted of aggressive sexual crimes tend to have higher testosterone levels than non- aggressive offenders and non-offenders (Stevens \& Cloete, 2010).

\section{Family Dynamics, Parenting Styles and Sexual Aggressive Behaviour of Adolescent Males}

Family is one of the most influential agents of socialization for adolescent males with the continuous consequence during adolescence. Healthy family dynamics typically work as open systems, allowing open communication, building trust and secure attachment and self- actualization for every member. However, lack of stability and growth could contribute towards various hazard aspects of aggression that are located in the family (Burton, 2007).

Parenting style plays a significant role in the foundation on how children will behave in their future and the manner in which parents discipline their children has much impact on the cognitive, emotional and social development (William, 2005). The majority of parents strive to channel their children's desires into socially acceptable behaviour and to educate them the skills and laws needed to function in their various social environments. Drawing from the four parenting styles pioneered by Diana Baumrind as cited in Bernstein et al. (2008), when parents and adolescents engage in socialization process, parents tend to display one of the four distinctive styles namely: authoritarian, permissive, authoritative and uninvolved parenting. 


\subsection{Authoritarian parents}

Authoritarian parents are parents that are more strict, punitive, unsympathetic, aggressive and difficult. They value obedience, try to mould their children's behaviour to meet a set standard but rigid in terms of promoting independence (Pastorino \& Doyle-Portillo, 2011). Adolescents from such households tend to internalize the aggression caused parents, which in turn results in struggling to form secure attachment with significant others (e.g. peers and sexual partners) (Weiten, 2011). Because of maltreatment and hostile environment such youth find themselves live in, they tend to perform poorly academically and become anti-social towards authority figures at school (Louw \& Louw, 2007). From McCrae and Costa's theory of personalities, they experience neuroticism (e.g depressed) while from Hans Eysenck's PEN model are described as psychotic (e.g. destructive) (Ryckman, 2008; Weiten, 2011). Taylor, Peplau and Sears (2006) point out that hostile family settings propel adolescent males to belong to a gang and abuse drugs and alcohol. To support this, Bezuidenhout and Joubert (2011) highlight that when they have unconsciously internalized their experiences, they become sexually aggressive to females, gang-rape lesbians and exploit those who claim to be gays (men who have sex with men).

\subsection{Permissive parents}

Various scholars (Jansen et al., 2012; Karla, 2010) describe permissive parents as accepting, too lenient and negligent and as a result their children tend to be immature, dependant, unhappy and request help even in slight difficulties. Louw and Louw (2007) argue that adolescent males of permissive parents are inextricably linked to more aggressive behaviour in the class room environment owing to inadequate skills acquired A quantitative study conducted in Western Cape, South Africa by Burton (2007) highlighted that $11 \%$ of black rural parents were permissive as compared to more than $60 \%$ of other races (i.e. Whites, Indians and Coloureds). Adolescents reared by permissive parents were reported as violent and unsympathetic towards others. In another research finding, National Youth Victimization revealed that $43 \%$ of sexual perpetrators stay with their permissive parents and most of these youth have left schooling (Ansell, 2005).

\subsection{Authoritative parents}

Authoritative parents are warm, caring, encourage independence despite setting limits and most likely to engage their adolescents in discussions that involve sexual matters (Pastorino \& Doyle-Portillo, 2011). From Vygotsky's point of view, Bruce (2005), supportive parents act as the scaffolding (temporary support) that helps adolescents to advance to the levels of behavioural development. Adolescent males living with authoritative parents have the ability to make informed decisions and solve their problems adequately because parents instil morals and values, which are necessary for sexual self-efficacy, identity moratorium and autonomy (Compton \& Hoffman, 2013; Decci \& Ryan, 2006) They are friendlier, cooperative, self-reliant and socially responsible (Bee \& Boyd, 2003). Therefore, good quality parents-child connection and communication as well as good family supervision are associated with minimal level of aggression among adolescents (Jemmott, Heeren, Ngwane, Hewitt, Jemmott, Shell \& Leary, 2007).

\subsection{Uninvolved parents}

Uninvolved parenting style, as compared to authoritative and authoritarian parenting styles, tend to be unresponsive to their children's needs. Adolescent males reared in households led by uninvolved parents are unable to form secure attachment and more likely to behave impulsively and aggressively (Karla, 2010). They are characterized by noncompliance, moodiness, poor self-regulation, confusion and have low self-esteem (Pastorino \& Doyle-Portillo, 2011). To claim their ego, such adolescent males may engage with multiple partners for sexual gratification and harass them when they refuse to engage in sexual activities (Holborn \& Eddy, 2011; Kopko, 2007). Thus, communications of parent and adolescents make adolescent males learn to make informed decisions and establish positive identity as opposed to experiencing an identity crisis (Bernstein et al., 2008; Nicholas, 2008; Weiten, 2011).

\subsection{Divorced and Orphan-hood}

In South Africa, as a multiple wounded country owing to its history prior 1994, a number orphans increases at an alarming rate due to a multiplicity of factors. In a study conducted on South African families revealed that, the deficiency of one or both parents negatively influence the adolescent's developmental behaviour (Jansen et el., 2012; Karla, 2010). However, 
adolescent males who are detached from their parent have a susceptibility to be negatively influenced by strangers and peers. Holborn and Eddy (2011) maintain that orphaned adolescents have high possibilities of dropping out of school, living in domestic settings with less basic needs (food and security) and experience anxiety and depression which adversely lead to lack of empathy or sympathy. Consequently, it is that lack of empathetic understanding which predisposes adolescents to sexual aggression. In the case of separation between parents (i.e divorce), adolescents become confused because they love both parents. Separated parents (most often being mothers who raise the children tend to be unemployed, often are emotionally stressed and tend to be less sympathetic, sensitive or even un-involved with their children (Lussier \& Healey, 2010). In trying to get loved and escape from confusion, adolescent males from divorced families join gangs which unconsciously force them to engage in aggressive sexual behaviours for conformity (Stevens \& Cloete, 2010).

\subsection{Homelessness and poverty}

According to Giddens (2009), homelessness is the condition where people have no residence to reside in, while poverty is defined as the condition of having insufficient requirements to survive (Jansen et al., 2012). The majority of homeless adolescents are being pushed over the periphery of homelessness and poverty by factors that are beyond their control (e.g. being an orphan, neglect, unemployed parents and criminal reputation of the family) (Nevid, 2012). They resort to some form of provisional accommodations even though the majority sleeps roughly on the streets. Consequently, adolescents who have been raised by poor parents or neglected, have greater possibilities of being school dropouts, exposed to multiple aggressors or provoking situations and live in streets without parental supervision (Holborn \& Eddy, 2011). Based on this information, this implies that lack of parental supervision desensitizes adolescents and contributes immeasurably to the vulnerability of males in particular (e.g. prone to sexual aggression, criminal behaviour).

\section{Cultural Norms as Precipitating Factor of Sexual Aggressive Behaviour of Adolescent Males}

Culture is defined as the manner in which a certain group of indigenous people behave, or else as a set of socially transmitted and cultured behavioural patterns, beliefs and customs (Preez, Durrheim, Eskell-Blokland, Freeman, Gcabo, Govender, Kaldine, Mokwena, Petersen, Radebe, Ratele, Semenya \& Zuma, 2012). Cultural socialization refers to parental practices that educate offspring about their racial or ethnic heritage to support cultural customs and traditions (Papalia et al., 2009; Preez et al., 2012). However, in South Africa, Swartz et al., (2010) argue that our cultural value system have always brought to abide in the way we judge unsafe sexual behaviour. For example in Xhosa tradition, traditional male circumcision indicates a rite of passage for the adolescent males from boyhood to manhood (Peltzer \& Kanta, 2009). This is credited to a strong cultural belief that unsafe sex is more enjoyable. Most scholars argue that adolescent boys that grow up in traditional villages that embrace culture and male dominance, such adolescents perceive aggression as a sign of their sexual ability and in preparation for their leading role in the household ((Bjorklund \& Blasi, 2012; Kassin et al, 2011). Drawing from ecological levels pioneered by Bronfenbrenner (Swartz et al., 2010), there is a fundamental mutual relationship between individual, interpersonal and societal levels of influence. Breet et al. (2010) found that the link between personal aggression and cultural beliefs preserve aggressive sexual behaviour among adolescent males, which in turn, regarded as a norm by adolescents. Jeriphanos, Kudakwashe and Phinias (2004), confirm that, according to African culture if a woman or a girl says "no" to sex, it means the opposite hence the result would be sexual victimization and subservient attitude expected from the females. Arguably, Petersen, Bhana and McKay (2005) point out that there is a rising concern about the escalating and destructive nature of aggressive sexual behaviour which hinders educational process among adolescent males. According to Kann (2008), the majority of high school females are faced by an overwhelming crisis of brutal aggressive sexual behaviour as they are subject to assaults by their adolescent males at school.

\subsection{School environment}

Schools are significant environments for child socialization and have a tendency of becoming more vital as male children get into adolescence. Schools promote socially acceptable behaviour and academic capabilities through having clear instructions and emphasize good behaviour among learners (Kassin, et al., 2011). These features articulate the school's competence to remunerate social behaviour and develop cognitive development, collective norms and behavioural modification (Burton, 2007; Charlesworth, 2004). Ballantine and Spade (2008) further emphasize that neighbourhood qualities influence school and the behavioural relationships of adolescents among peers. Thus, school neighbourhoods 
have additional effects on adolescent's behaviour than their geographical area in which they live-in. However, socially disorganized school neighbourhoods are incapable of supporting the expected societal values of their inhabitants and end up in producing irresponsible citizens. Majority of South African rural high schools being disorganized in terms of structures and limited resources, it becomes a challenge for the educators to accomplish the mission of promoting academic capacity and emphasize socially acceptable behaviour. In turn, adolescent males owing to lack of cognitive stimulation may resort to anti-social behaviour (e.g risky sexual behaviour (Stevens \& Cloete, 2010). In the study conducted in Cape Town by Burton (2007), adolescent males who study in schools dominated by drugs and where violence and sexual offences were common, resorted to sexually aggressive behaviour as opposed to adolescent males from affluent neighbourhoods.

\section{Consequences of Adolescent Males' Aggressive Sexual Behaviour}

\subsection{Unplanned fatherhood}

Fatherhood at an early age and immediate conditions have adverse effects to the child and the adolescent father. Ashford and LeCroy (2010) argue that adolescent fathers are themselves prone to developmental problems which will restrain their ability to bond with their babies. For example, they have to attend school and simultaneously serve children roles in the family which at some times will not be possible for teen-parent to interact with the infant. Furthermore, huge numbers of adolescent parents live under poverty line and likely to have many children if they are in cohabitation with their babies' mothers (Ashford \& LeCroy, 2010; Langa 2010).

\subsection{Sexual transmitted infection and HIV/ AIDS}

Majority of South African adolescents have grown up in risky societies and vulnerable families to the HIVIAIDS pandemic. HIVIAIDS as a sexual transmitted disease, is transmitted during unsafe sex. However, literature revealed that the majority of sexual aggressive adolescent males do not use condom (Holborn \& Eddy, 2011; Jewkes, 2011), resulting in transmitting and being infected with sexual infections (gonorrhea, syphilis, and herpes) particularly HIVIAIDS (Louw \& Louw, 2007).

\subsection{Imprisonment}

The fundamental belief of the contemporary South African penitentiaries (prisons) is to restructure the adolescent detainee's behaviour and also prepare them to participate in an acceptable manner in their societies after released (Steven, 2010). Drawing from the constitution (Act No. 200 of 1993) in a criminological perspective, punishment is defined as the enforcement of law through inflicting pain or grief on the perpetrator by the State (Stevens \& Cloete, 2010). Although imprisonment is a used legal form of punishment, it does not discourage and completely prevent adolescent's aggressive sexual behaviour. Popovac and Jantjies (2011) found that adolescent males as young as under 18 years of age were incarcerated. Finally, Jewkes (2012) found that adolescent males who were sexual offenders against children were much more likely to have histories of sexual abuse than non -sexual offenders.

\subsection{Unemployment}

In South African adolescent males commit crime at an early age which leads them to have criminal record. Beside lack of skills caused by imprisonment (Giddens, 2009), their criminal records hinder them from acquiring vocational training or jobs (Jansen et al., 2012). By 2011, according to study conducted by Umsobomvu, the unemployment rate amongst youth was 68\% for age group (18-35) (Holborn \& Eddy, 2011). From this perspective, unemployed youth may mask their frustrations by resorting to alcohol and be sexually aggressive.

\subsection{Post-traumatic stress}

The majority of black South African adolescents have experienced quite a lot of serious trauma before reaching the age of 20. According to Steinberg, Vandell and Bornstein (2011) symptoms for traumatized adolescents have unpleasant effects that comprises intrusive thoughts and flash backs, nightmares, social withdrawn and problem with emotional control. Therefore, it is that lack of emotional control that predisposes adolescents to sexual aggressive behaviour. 
Hence, most adolescent who have been victims of sexual offence can have lasting problems. Sexual offenders tend to have problem (of being stressed and have guilty feelings) when they get rehabilitated (Lanchman et al., 2012). The study conducted amongst grade 8 to11 adolescents males in Cape Town by Holborn and Eddy (2011), show that $21 \%$ were perpetrators of sexual offences, while $16 \%$ use anger against their partners. Furthermore, $55 \%$ of school going adolescent females aged 12 to 20 live in fear of being sexually assaulted.

\subsection{Self- esteem}

Sense of confidence plays a fundamental role in adolescent's behaviour. Baumeister and Bushman (2011), define selfesteem as the way in which an individual assess and evaluate himself. Thus, adolescents with high self-esteem embrace positive views, capable and have good morality. Contrary, adolescents with low self-esteem consider themselves as being useless and immoral, as a result they become hopeless. It is that hopelessness that causes an unfavorable behavioural outcome that consists of recidivism and suicide (Ballantine \& Spade, 2008).

\subsection{Suicide}

Suicidal ideations are gradually increasing in rural areas resulted from escalation in psychological discomfort caused by accelerated incidence of aggression. According to Nicholas (2008) suicide refers to a premeditated death, in which an individual consciously strategize to end his or her own life. Suicide rates are high in anomic (normless) societies as compared to societies that set clear standards to obtain acceptable societal goals (Giddens, 2009). Suicide constitutes approximately $10 \%$ of unnatural deaths, while $30 \%$ of adolescent's suicidal propensity emanated from sexually victimized and sexual offending. Therefore, depressed and abused adolescents find themselves in circumstances where there is no answer, consequently resort to suicide (Ansell, 2005; Louw \& Louw, 2007).

\section{Conclusion and Implications for Practice}

In conclusion, the most riskier sexual behaviours consist of having unprotected sex with multiple partners and adolescents who grow up in dysfunctional families are prone to such undesirable behaviour. Additionally, a variety of factors which include poverty, socialization, economic, culture and others lead to sexual aggression. Aggressive sexual behaviour has adverse outcomes which encompasses sexual transmitted infections, imprisonment and unplanned fatherhood.

In the reviewed related literature, as researchers we have discovered methods which are believed to be appropriate for minimizing sexual aggressiveness of adolescent males. These methods are listed as follows:

- Parent should provide sessions of sex education and personal responsibility with their children.

- Prosperous neighbours are expected to have specialized and administrative professions which allow them to make necessities of their children available and give encouraging role models

- Government must employ more officials and social advocates (social workers and psychologists).

- Establish of campaigns to encourage older men to support young adolescents to enhance good behaviour.

- Concerning the risk of adolescents, literature illustrate that there is a strong need for establishment of healthcare centres to treat psychological effects.

\section{Acknowledgements}

The authors gratefully acknowledge financial support from the Govan Mbeki Research and Development Centre.

\section{References}

Ansell, N. (2005). Children, Youth and Development: Perspectives on Development. Routledge: New York. Ashford, B.J. \& LeCroy, C.W. (2010). Human behaviour in the Social Environment. Cengage Learning: United State of America: Ballantine, B. H. \& Spade, Z. J. (2008). Schools and Society: a sociological approach to education. Sage publications Ltd: United State of America.

Baumeister, R.F. \& Bushman, B.J. (2011). Social Psychology and Human Nature. Wadsworth Cengage Learning: Canada. Bee, D. \& Boyd, D. (2003). Life-span development: Study edition. (3rd edition.). Allynn \& Bacon: Boston.

Bernstein, D.A., Penner, L.A., Clark-Stewart, A. \& Roy, E.J. (2008). Psychology. Houghton Mifflin: United State of America: Bernstein, C.S. \& Penner, R. (2012). Psychology. China: Wardsworth cangage learning. 
Bezuidenhout, C. \& Joubert, S. (2011). Child and Youth misbehaviour in South Africa: a Holistic approach. Van Schaik: Pretoria.

Bjorklund, D.F \& Blasi, C.H (2012). Child and Adolescent Ddevelopment: An integrated approach. Linda Schreiber-Ganster: Canada.

Breet, L., Myburgh, C. \& Poggenpoel, M. (2010). The relationship between the perception of own locus of control and aggression of adolescent boys. South African journal of education: 30,511-526.

Bruce, H.H. (2005). Psychology the essence of a science. Pearson Education: New York.

Burton, P. (2007). Someone stole my smile: An exploration into the causes of youth violence in South Africa. Centre for justice and crime prevention: Cape Town.

Charlesworth, R. (2004). Understanding child development. Delmar Learning: United State of America.

Deci , E.L. \& Ryan, R.M. (2006).Hedonia, Eudaimonia, and Well-Being: An Introduction. Journal of Happiness Studies, (9), 1-11.

de Vos, A.S., Fouche, C.B., Strydom, H. \& Delport, C.S.L. (2011). Research at grass roots. Van Schaik: Pretoria.

Engler, B. (2014). Personality Theories. Cengage Learning: Belmont.

Giddens, A. (2009). Anthony Giddens Sociology. Polity Press: United Kingdom.

Glieds, S. \& Pine, D.S. (2002). Consequences and correlates of adolescent depression. Archives of Pediatrics and Adolescent Medicine, 156:1009-1014.

Holborn, L. \& Eddy, G. (2011).First steps to the healing the South African family. South African Institute of Race Relations: Richmond.

Jansen, J., Moletsane, M., Neves, D., Soudien, C., Stroud, L., Swart, S. \& Wild, L. (2012). Child and adolescent development. Oxford University Press. Cape Town.

Jemmott, J., Heeren, Z., Ngwane, N., Hewitt, L.S., Jemmott, R. \& O' Leary, A. (2007). Theory of planned behaviour pridictors of intention to use condoms among Xhosa adolescents in South Africa, Aids Care 19(5): 677-684.

Jeriphanos, M., Kudakwashe, M., Phinias, T. (2004). Influences of culture on acquaintance rape among college students. Thesis. Zimbabwe University: Harare

Kann, L. (2008). A dangerous game: male adolescent's perceptions and attitudes towards sexual consent. University of Witwatersrand: Johannesburg.

Karla, K. (2010). Pretend Aggression in play, aggressive behaviour and parenting style. Western Cape.

Kassin, S., Fein, S. \& Markus, H. R. (2011). Social Psychology:Wadsworth Cengage Learning: United State of America

Katy, M., Louis, D., Jeffley, E., Scott, E., Vijay, S., Molly, B., David, B., Jackie, B.,Salome, S \& Susan, P. (2002). The big picture with westen's highly accessible approach to psychology. John Wiley and Sons: New York.

Lanchman, A., Nassen, R., Hawkridge, S. \& Emsley, R. (2012). A Retrospective chart view of the clinical and psychosocial profile of psychotic adolescents with co-mobid substance use disorders presenting to acute adolescent psychiatric services at Tygerberg Hospital. Depertment of psychiatry,faculty of health Stellenbosch University, Vol. 18 № 2 pp. 53-60.

Langa, M. (2010). Adolescent's talk about absent fathers. Journal of Psychology in Africa, 20(4) 519- 526.

Louw, D. \& Louw, A. (2007). Child and adolescent development. University of Free State: Bloemfontein.

Lussier, P. \& Healey, J (2010). Searching for the developmental origions of sexual violance. John wiley \& sons: Canada.

Mouton, J. (2012). Understanding social research. Van Schaik: Pretoria.

Mwinga, A. M. (2012). Factors contributing to unsafe sex among teenagers in the secondary schools of Botswana. University of South Africa: Pretoria

Nevid, J.S. (2012). Essentials of psychology: concepts and applications. Cengage learning: Australia.

Nicholas, L. (2008). Introduction to Psychology. UCT Press: Cape Town.

Papalia, D.E., Olds, S.W. \& Feldman, R.D. (2009). Human development. McGraw-hill: New York.

Pastorino, E. \& Doyle-Potillo, S. (2011). What is Psychology. Wadsworth Cengage Learning: Australia.

Peltzer, K. \& Kant, X. (2009). Medical circumcision and manhood initiation rituals in the Eastern Cape, South Africa: a post intervention evaluation. Culture, Health and sexuality, pp. 83- 97.

Phaswana, N., Seage, J., Peitzer, K., Jooste, S. \& Mkhonto, S. (2010). Social determinant of HIV in the Eastern Cape. Human research Council: Eastern Cape.

Preez, E., Durrheim, K., Blockland, L., Freeman, M., Gcabo, R., Govender, K. M., Kaldine, F., Mokwena, M., Petersen, I., Radebe, N.B., Ratele, K., Semenya, B. \& Zuma, B. (2012). Community psychology in South Africa. Van Schaik : Pretoria.

Ryckman, R.M. (2009). Theories of Personality. Thomson Wadsworth: Belmont.

Sadock, B. J. \& Sadock, V. A. (2007). Kaplan \& Sadock's synopsis of psychiatry: behavioral Sciences/ clinical psychiatry. Lippincott Williams \& Wilkins: China.

Steinberg, L., Vandell, D.L. \& Bornstein, M.H. (2011). Development: Infancy through Adolescence. Canada: Wadsworth Cengage Learning.

Steven, L.B. (2010). Crime Prevention: Approaches, practices and evaluations. Anderson: United States of America.

Stevens, R. \& Cloete, M. G. T. (2010). Introduction to Criminology. Oxford University Press: Cape Town.

Swart, L., De la Rey, C., Duncan, N. \& Townsend, S. (2008). An introduction to Psychology. Oxford University Press: Cape Town.

Swartz, L., de la Rey, D., Duncan, N. \& Townsend, L. (2010). Psychology: An introduction. Oxford University Press: Cape Town.

Taylor, S.E., Peplou, L.A. \& Sear, D.O. (2008). Social Psychology.: Pearson Prentice Hall: United State of America.

Ward, T. (2002). Marshall and Barbaree's integrated theory of child sexual abuse: A critique. England: Routledge.

Weiten, W. (2011). Psychology Themes and variations. Cengage: Australia:

William, C. (2005). Theories of development. New York: Pearson. 